\title{
Prison smoking bans: clearing the air
}

$\mathrm{T}$ hey end up behind bars for numerous reasons, but most prison inmates have one thing in common: they smoke.

"With such a high prevalence of smoking, the air is kind of unbreathable at times," says Benoit Lasnier, scientific advisor for the Institut National de Santé Publique du Québec. "The fact is, a lot of inmates are smokers. It's part of the culture in prisons."

Increasingly, however, governments are trying to change that part of prison culture. In 2014, Quebec will become the last province in Canada to ban smoking anywhere in its provincial prisons. The province has already banned smoking indoors, though it doesn't seem to be working all that well.

A 2011 survey of 113 Quebec inmates in three provincial correctional facilities found a smoking rate of $80 \%$, and $93 \%$ of those smokers reported using tobacco products indoors despite the ban (Can J Public Health 2011;102:249-53). Only 46\% had been caught in the act, and $58 \%$ of those caught weren't punished for violating the indoor ban.

A complete ban would be more effective, suggests Lasnier, because inmates would not be permitted to even own cigarettes. The province will also provide smoking-cessation services. "Inmates need to be shown methods to quit smoking," says Lasnier. "Many of them want to quit smoking but it's not the ideal environment. There is a lot of stress."

Smoking has been banned in federal prisons in Canada for a number of years. The Correctional Service of Canada (CSC) rolled out the ban in stages. It announced its goal to eliminate secondhand smoke in federal penitentiaries in 2005, instituted an indoor ban in 2006, reported its intent to move to a complete ban in 2007 and, finally, implemented the total ban in 2008 .

"Staff and offenders were given significant advance notice so that they can take necessary steps to prepare themselves for the total smoking ban," Véronique Rioux, a media relations officer for CSC, writes in an email. "CSC also provided staff, offenders and volunteers with educational materials to help them learn how to quit smoking."

Prison smoking bans are not only commonplace in Canada but also in other jurisdictions around the world. In North Carolina, a ban resulted in a $77 \%$ decrease of respirable suspended particulates, a marker for secondhand smoke (Tob Control 2008;17:123-7). A smoking ban in a prison in Switzerland also led to much-improved air quality (Tob Control 2012;21:488-91).

Less encouraging were the results of a study that examined the resumption of smoking after release from a tobaccofree facility ( $\mathrm{J}$ Correct Health Care $2009 ; 15: 190-6)$. The survey of 200 released inmates found that $83 \%$ were smokers. Of those, $37.3 \%$ reported abstaining from smoking at the end of their first day outside prison. That percentage fell to $17.7 \%$ after a week and plummeted to $3.1 \%$ after six months. Roger Collier, CMAJ

CMAJ 2013. DOI:10.1503/cmaj.109-4486

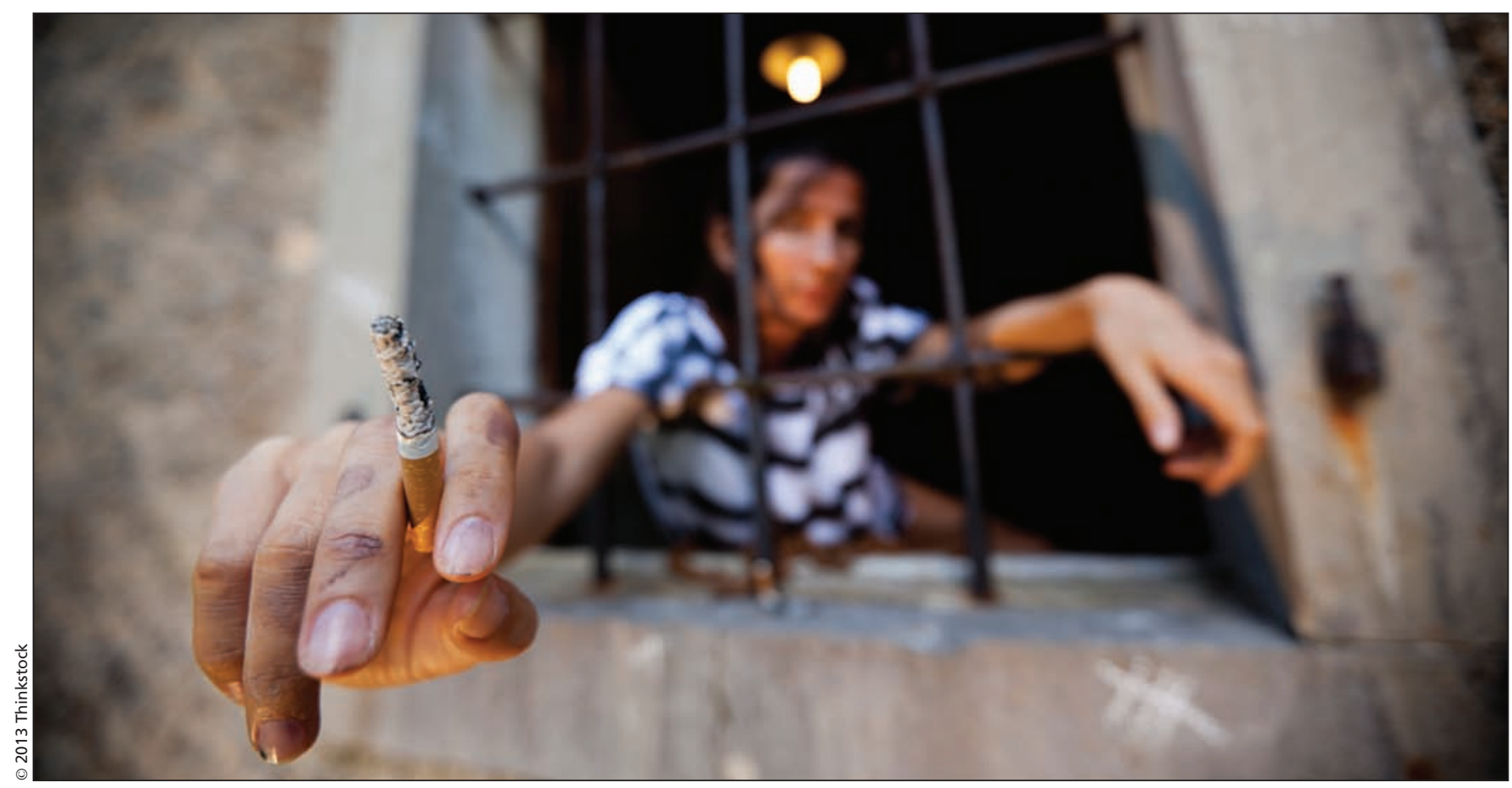

Smoking is part of prison culture, with prevalence rates exceeding $80 \%$ in some facilities. 